\title{
ROPIVACAINE HYDROCHLORIDE 0.2\% LOCAL INFILTRATION AND INTRAPERITONEAL INSTILLATION FOR POSTOPERATIVE PAIN RELIEF IN CAESAREAN SECTION UNDER SPINAL ANAESTHESIA: A RANDOMISED CLINICAL STUDY
}

\author{
Anju Gautam ${ }^{1}$, Bhupendra Muzalda², Neelima Tandon ${ }^{3}$ \\ ${ }_{1}^{1}$ Assistant Professor, Department of Anaesthesiology, G. R. Medical College, Gwalior, Madhya Pradesh. \\ 2 Postgraduate Student, Department of Anaesthesiology, G. R. Medical College, Gwalior, Madhya Pradesh. \\ ${ }^{3}$ Associate Professor, Department of Anaesthesiology, G. R. Medical College, Gwalior, Madhya Pradesh.
}

\begin{tabular}{l}
\hline ABSTRACT \\
BACKGROUND \\
The purpose of this study was to compare Inj. Ropivacaine $0.2 \%$ local infiltration and intraperitoneal instillation with Inj. \\
Ropivacaine $0.2 \%$ local infiltration alone for postoperative pain relief in caesarean section under spinal anaesthesia.
\end{tabular}

\section{MATERIALS AND METHODS}

Pregnant patients of ASA grade I and II posted for caesarean section under spinal anaesthesia were randomised into 3 groups (Group I, II, III of 30 patients each). Patients in group I received no local infiltration; patients in group II were given local infiltration of $20 \mathrm{~mL}$ Inj. Ropivacaine $0.2 \%$ at incision site before closure of skin; patients in group III received intraperitoneal instillation of 5 $\mathrm{mL}$ Inj. Ropivacaine $0.2 \%$ before closure of peritoneum and local infiltration of $15 \mathrm{~mL}$ Inj. Ropivacaine $0.2 \%$ at incision site before closure of skin. In the postoperative period, pain assessment was carried out by VAS and duration of analgesia was calculated as the time taken from the onset of sensory block to the first request for supplemental analgesia. Haemodynamics and side effects were also recorded in all patients.

\section{RESULTS}

A significant longer duration of analgesia was observed in group II and group III $(p<0.05)$ as compared to group I. The mean $( \pm$ SD) duration of analgesia in group I, II and III was $115.67 \pm 4.09,147.17 \pm 4.67$ and $170.33 \pm 3.69$ min. respectively. Significantly lower VAS scores were observed in group II and III as compared to group I. The mean ( \pm SD) VAS scores at first analgesic request were as follows:

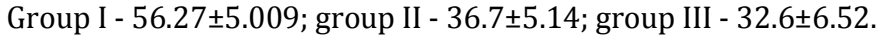

\section{CONCLUSIONS}

We recommend the use of Inj. Ropivacaine $0.2 \%$ local infiltration and intraperitoneal instillation as it produces better postoperative analgesia in caesarean section as compared to Inj. Ropivacaine $0.2 \%$ local infiltration alone under spinal anaesthesia.

\section{KEYWORDS}

Intraperitoneal Instillation, Ropivacaine, Caesarean Section, Spinal Anaesthesia.

HOW TO CITE THIS ARTICLE: Gautam A, Muzalda B, Tandon N. Ropivacaine hydrochloride 0.2\% local infiltration and intraperitoneal instillation for postoperative pain relief in caesarean section under spinal anaesthesia: A randomised clinical study. J. Evolution Med. Dent. Sci. 2016;5(78):5816-5819, DOI: 10.14260/jemds/2016/1312

\section{BACKGROUND}

Prompt and adequate postoperative pain relief is an important component of caesarean delivery that can make the period immediately after the operation less uncomfortable as well as mother can initiate early breastfeeding that helps to contract the uterus and accelerates the process of uterine involution in the postpartum period.

Short- or medium acting sedatives, narcotics and local anaesthesia have been employed during the operation as an adjunct to anaesthesia or to alleviate postoperative pain. Local anaesthetics cause reversible blockade of impulse propagation along the nerve fibres by preventing the influx of sodium ions through the cell membrane of the fibres. Several studies have

Financial or Other, Competing Interest: None.

Submission 24-08-2016, Peer Review 16-09-2016,

Acceptance 23-09-2016, Published 29-09-2016.

Corresponding Author:

Anju Gautam,

Koteshwar Colony, In front of Koteshwar Mandir,

Near Anand Marg School,

Gwalior-474003, Madhya Pradesh.

E-mail:mddranju@gmail.com

DOI: $10.14260 /$ jemds/2016/1312 reported on use of pre-emptive local anaesthetics (local anaesthetic given during the operation to prevent or reduce pain afterwards) to relieve postoperative pain, with results ranging from being beneficial ${ }^{1,2}$ to conferring no benefit. . $^{3,4}$

The local anaesthetic may be administered by pre or postincisional abdominal nerve block (local anaesthetic injected to block the nerves before cutting the skin at the beginning of the operation, or after closing the skin at the end $)^{5}$ or pre- or postincisional abdominal wound infiltration. ${ }^{1,6}$ Local anaesthetics eventually get absorbed systemically and secreted in breast milk, but their effects on breastfed babies have not yet been documented. This is in sharp contrast to morphine or pethidine, both of which have significant transfer to breast milk and may have a sedative effect on the baby.

Ropivacaine is an amide type of local anaesthetic that is structurally related to bupivacaine. Unlike bupivacaine, which is present in a racemic mixture, ropivacaine is exclusively the $S(-)$ enantiomer. Various clinical studies has shown that ropivacaine is equal to bupivacaine in local anaesthetic potency and is less toxic than bupivacaine in regard to the production of mild central nervous system and cardiovascular toxicity by intravenous infusion. ${ }^{1}$ 


\section{MATERIALS AND METHODS}

After ethical committee approval and written informed consent, this randomised, prospective clinical observational study was carried out on 90 pregnant patients undergoing Caesarean section of ASA grade I \& II scheduled under spinal anaesthesia. Criteria for exclusion were; allergic reactions to local anaesthetics, peripheral or central neurological disease, raised intracranial tension, valvular heart diseases, significant ECG changes, renal diseases, endocrinal diseases, metabolic diseases, hepatic diseases, coagulopathy and bleeding disorders. Parturients were also excluded from the study if the procedure was performed under general or epidural anaesthesia. Ninety Pregnant women who fulfilled the eligibility criteria were chosen, explained about the procedure and written consent was taken. Patients were subsequently randomised into three groups of 30 each.

Group I (n=30) - Control group with no local infiltration.

Group II (n=30) - Local infiltration of $20 \mathrm{~mL}$ Inj. Ropivacaine $0.2 \%$ at incision site.

Group III (n= 30) - Local infiltration of $15 \mathrm{~mL}$ inj. Ropivacaine $0.2 \%$ at incision site and intraperitoneal instillation of $5 \mathrm{~mL}$ Inj. Ropivacaine $0.2 \%$.

Assessment of pain was done by Visual Analogue Scale (VAS) [Table 1]. During the preoperative interview, subjects were familiarised with the recording of scale. The top of the scale at 100 represents very severe pain while the baseline value-0 represents no pain.

On entering into the OT, after placement of standard noninvasive monitoring devices, all patients were given spinal anaesthesia using Inj. Bupivacaine $0.5 \%$ heavy according to the standard protocol. Patients in group I received no local infiltration; patients in group II were given local infiltration of $20 \mathrm{~mL}$ Inj. Ropivacaine $0.2 \%$ at incision site before closure of skin ; patients in group III received intraperitoneal instillation of $5 \mathrm{~mL}$ Inj. Ropivacaine $0.2 \%$ before closure of peritoneum and local infiltration of $15 \mathrm{~mL}$ inj. Ropivacaine $0.2 \%$ at incision site before closure of skin .The level of sensory block was assessed using a 26 gauge needle and recorded as loss of sensation to pinprick, checking in a caudal to cephalic direction. Motor block was recorded according to the Bromage scale [Table 2]. Baseline observations were recorded before spinal anaesthesia. Pulse rate, electrocardiogram, systolic and diastolic blood pressure, respiratory rate and peripheral arterial haemoglobin oxygen saturation were monitored perioperatively. Data monitoring performed continuously, but for statistical analysis data were recorded at $0,5,10,20,30$, 45, 60 minutes after intrathecal injection and thereafter every hour up to 8 hours.

Fluid administration was continued and a decrease in mean arterial pressure greater than $30 \%$ below the preanaesthetic baseline value was treated with inj. Mephentermine IV \& intravenous fluids. In the postoperative period, pain assessment was carried out by VAS and duration of analgesia was calculated as the time taken from the onset of sensory block to the first request for supplemental analgesia. When patients complained of pain postoperatively, VAS score at the time of first analgesia request was recorded. Then intramuscular diclofenac sodium $75 \mathrm{mg}$ was prescribed and the study of that patient was taken as complete.

Patients were closely observed in the intraoperative and postoperative period for complications like nausea, vomiting, dyspnoea, respiratory depression, chest pain, shivering, dysrhythmia, bradycardia, hypotension and any other.

The observations were recorded and subject to statistical analysis using student's " $t$ " test by statistics calculator Epi Calc. 2000 s, p-value $<0.05$ taken statistically significant.

\section{Table 1: VAS Score Rating}

0 : No Pain

1-25: Mild Pain

26-50: Moderate Pain

51-75: Severe Pain

76-100: Very Severe Pain

Scale

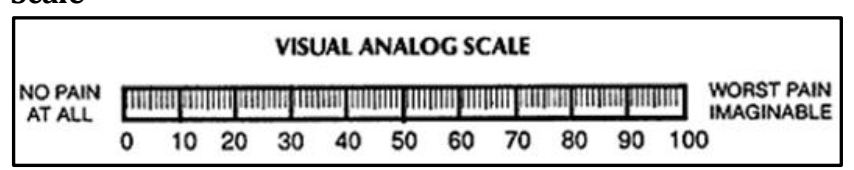

\section{Table 2: Bromage Score}

\section{Grade criteria}

Grade 0 - Free movement of leg and feet

Grade 1 - Just able to flex knees with free movement of feet Grade 2 - Unable to flex knees and barely able to move feet Grade 3 - Unable to move legs and feet

\section{RESULTS}

A total of 90 patients were recruited and studied. The three groups were comparable with respect to age, weight, height and duration of surgery [Table 3].

There was no significant changes in pulse rate, systolic blood pressure, diastolic blood pressure and respiratory rate among three groups ( $\mathrm{p}>0.05)$.

\begin{tabular}{|c|c|c|c|}
\hline \multirow{2}{*}{ Variable } & $\begin{array}{c}\text { Group I } \\
(\mathbf{n = 3 0 )}\end{array}$ & $\begin{array}{c}\text { Group II } \\
(\mathbf{n = 3 0 )}\end{array}$ & $\begin{array}{c}\text { Group III } \\
(\mathbf{n}=\mathbf{3 0})\end{array}$ \\
\cline { 2 - 4 } & Mean \pm SD & Mean \pm SD & Mean \pm SD \\
\hline Age (yrs.) & $24.37 \pm 3.65$ & $26.5 \pm 5.871$ & $25.1 \pm 4.4$ \\
\hline Weight (Kg) & $57.6 \pm 5.31$ & $58.2 \pm 5.1$ & $57.3 \pm 5.57$ \\
\hline Height (cm) & $151.7 \pm 3.21$ & $150.73 \pm 3.16$ & $150.97 \pm 2.73$ \\
\hline \multicolumn{4}{|c|}{ Table 3: Comparison between Demographic } \\
Data in all the Three Groups \\
\hline
\end{tabular}

The mean $( \pm \mathrm{SD})$ duration of analgesia in group I, II and III was $115.67 \pm 4.09, \quad 147.17 \pm 4.67$ and $170.33 \pm 3.69 \mathrm{~min}$ respectively. On comparison and application of statistical analysis, there was significant prolongation in duration of analgesia between group I \& II, group II \& III and group I \& III, i.e. there is significant prolongation of duration of analgesia in group II and group III $(\mathrm{p}<0.05)$ compared to group I [Graph 1].

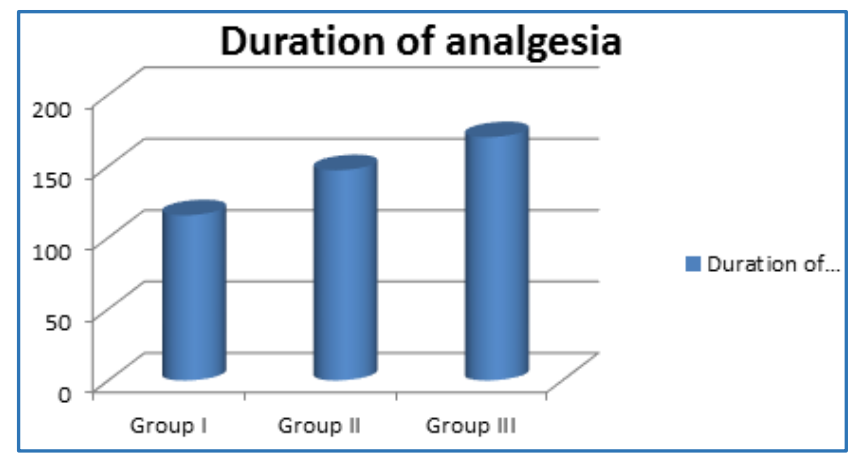

Graph 1: Comparison of Mean ( \pm SD) Duration of Analgesia in all the Three Groups 
The mean $( \pm \mathrm{SD})$ VAS score at first analgesic request in group I was $56.27 \pm 5.009$, group II was $36.7 \pm 5.14$ and group III was $32.6 \pm 6.52$ respectively. There was significant $(\mathrm{p}<0.05)$ reduction in VAS score in group II and group III when compared to group I [Graph 2].

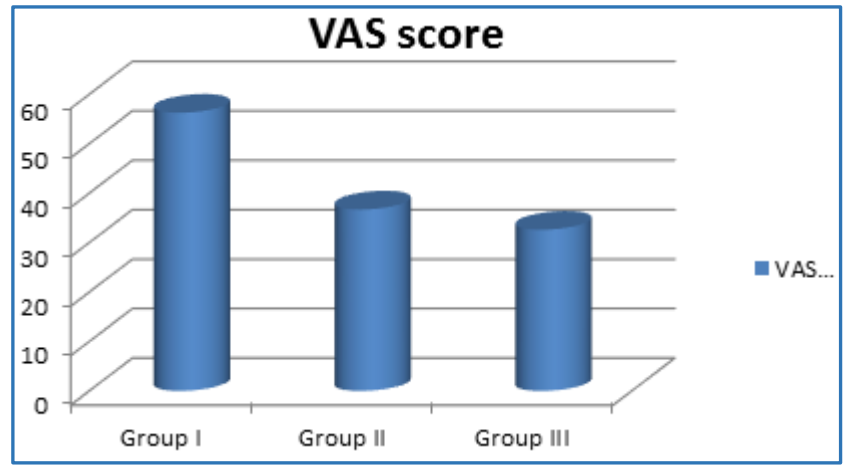

\section{Graph 2: Comparison of Mean ( \pm SD)} VAS Score in all the Three Groups

The incidence of nausea and vomiting in group II was significantly higher $(6.67 \%)$ as compared to group I and III $(3.33 \%)$. Similarly, incidence of shivering in group I was $13.33 \%$ as compared to $10 \%$ in group II and III. None of the patients in all the three groups had hypotension, bradycardia, dyspnoea, chest pain and dysrhythmia.

\section{DISCUSSION}

Minimising pain after caesarean section is best achieved using a multimodal approach. Local anaesthetics, ranging from lidocaine to the more recent ropivacaine, have been used as pre-emptive analgesics. The findings of this study indicate that Inj. Ropivacaine $0.2 \%$ local infiltration with intraperitoneal instillation prolongs the duration of analgesia and provides good analgesia (Lower VAS score)as compared to $0.2 \%$ ropivacaine local infiltration alone.

Local infiltration around the wound site, and even deeper in the surgical cavity, can suppress the generation and propagation of injury-induced discharge during surgical manipulations. This action may be due, in part, to inhibition of the transduction and sensitisation steps in nociception for certain local anaesthetics, for example, bupivacaine and amethocaine have been shown to block a transducing channel TRPV1-1 that plays a key role in the development of hyperalgesia after injury or inflammation. ${ }^{7}$ It is noteworthy that lidocaine has been shown to activate this channel, which may account for the stinging pain that accompanies s.c. injection of this local anaesthetic. ${ }^{8}$ Continuous delivery of local anaesthetics, from slow-release formulations or temporarily placed catheters, may extend such impulse inhibition for days after surgery. Local anaesthetics can also inhibit inflammatory and local sensitising responses, by directing suppressing some phases of inflammation, that is, neutrophil priming ${ }^{9}$, and by blocking some of the neuronal pathways that are activated by inflammation, that is, protein kinase $\mathrm{C}$, and certain $\mathrm{G}$ proteincoupled receptors. 9,10

The mean $( \pm$ SD) duration of analgesia in group I, II and III was $115.67 \pm 4.09,147.17 \pm 4.67$ and $170.33 \pm 3.69 \mathrm{~min}$. respectively so there is significant prolongation of duration of analgesia in group II and group III $(\mathrm{p}<0.05)$ compared to group I.
Nguyan K et al ${ }^{11}$ also found that ropivacaine infiltration in caesarean section significantly increased the time interval to rescue analgesias compared to the control group. Labaille $\mathrm{T}$ et $\mathrm{al}^{12}$ showed that intraperitoneal instillation of Ropivacaine before and after the laparoscopic surgery significantly reduces the postoperative pain compared to placebo. Similar results were obtained from other studies. 13,14,15,16

The mean $( \pm S D)$ VAS score at first analgesic request in group I was $56.27 \pm 5.009$, group II was $36.7 \pm 5.14$ and group III was $32.6 \pm 6.52$ respectively which shows that there was significant reduction in VAS score in group II and group III when compared to group I.

Bonnet $\mathrm{V}$ et $\mathrm{al}^{17}$ also showed that ropivacaine infiltration after haemorrhoid surgery lowered the VAS scores significantly and total consumption of morphine decreased. Callesen $\mathrm{T}$ et al ${ }^{18}$ showed that ropivacaine for combined field block and intraperitoneal instillation for pain management after laparoscopic sterilisation has significantly lesser cumulative pain score compared to placebo group during mobilisation and coughing. The maximum difference in pain scores was seen $1 \mathrm{hr}$. after operation, but after $4 \mathrm{hrs}$. there was no difference between groups.

Similar conclusions have been reported from other studies. $19,20,21,22$

\section{CONCLUSION}

This clinical study demonstrated that Inj. Ropivacaine $0.2 \%$ local infiltration and intraperitoneal instillation produces better postoperative analgesia in caesarean section as compared to Inj. Ropivacaine $0.2 \%$ local infiltration alone under spinal anaesthesia. Inj. Ropivacaine $0.2 \%$ local infiltration with intraperitoneal instillation also prolonged the duration of analgesia and provided good analgesia (Lower VAS score) as compared to $0.2 \%$ Ropivacaine local infiltration.

\section{REFERENCES}

1. Ganta R, Samra SK, Maddineni VR, et al. Comparison of the effectiveness of bilateral ilioinguinal nerve block and wound infiltration for postoperative analgesia after caesarean section. Br J Anaesth 1994;72(2):229-30.

2. Johanssen B, Hallerback B, Stubberod A, et al. Preoperative local infiltration with ropivacaine for postoperative pain relief after inguinal hernia repair. A randomised controlled trial. Eur J Surg 1997;163(5):371-8.

3. Adams WJ, Avramovic J, Barraclough BH. Wound infiltration with $0.25 \%$ bupivacaine not effective for postoperative analgesia after cholecystectomy. Aust NZ J Surg 1991;61(8):626-30.

4. Fredman B, Zohar E, Tarabykin A, et al. Bupivacaine wound instillation via an electronic patient-controlled analgesia device and a double-catheter system does not decrease postoperative pain or opioid requirements after major abdominal surgery. Anesth Analg 2001;92(1):189-93.

5. Trotter TN, Hayes-Gregson P, Robinson S, et al. Wound infiltration of local anaesthetic after lower segment caesarean section. Anaesthesia 1991;46(5):405-7.

6. Das KA, Wig J, Dhaliwal L. Pre-incisional local infiltration of bupivacaine and a mixture of bupivacaine and morphine for pain following lower segment cesarean section: a comparative evaluation. J Anaesthesiol Clin Pharmacol 1999;15(3):317-20. 
7. Komai H, McDowell TS. Differential effects of bupivacaine and tetracaine on capsaicin-induced currents in dorsal root ganglion neurons. Neurosci Lett 2005;380(1-2):21-5.

8. Leffler A, Fischer MJ, Rehner D, et al. The vanilloid receptor TRPV1 is activated and sensitized by local anaesthetics in rodent sensory neurons. J Clin Invest 2008;118(2):763-76.

9. Li Y-M, Maggio J, Wingrove D, Too HP, et al. Local anesthetics inhibit substance $\mathrm{P}$ binding and evoked increases intracellular $\mathrm{Ca} 2+$. Anesthesiology 1995;82(1):166-73.

10. Amir R, Argoff CE, Bennett GJ, et al. The role of sodium channels in chronic inflammatory and neuropathic pain. J Pain 2006;7(5 Suppl 3):S1-29.

11. Nguyen NK, Landais A, Barbaryan A, et al. Analgesic efficacy of Pfannenstiel incision infiltration with ropivacaine $7.5 \mathrm{mg} / \mathrm{mL}$ for caesarean section. Anesthesiology Research and Practice, Article ID 542375, 2010;2010:7.

12. Labaille T, Mazoit JX, Paqueron X, et al. The clinical efficacy and pharmacokinetics of intraperitoneal ropivacaine for laparoscopic cholecystectomy. Anesth Analg 2002;94(1):100-5.

13. Mulroy MF, Burgess FW, Emanuelsson BM. Ropivacaine $0.25 \%$ and $0.5 \%$ but not $0.125 \%$ provide effective wound infiltration analgesia after outpatient hernia repair, but with sustained plasma drug level. Regional anesthesia and pain medicine 1999;24(2):136-41.

14. Pasqualucci A, De Angelis V, Riccardo C, et al. Preemptive analgesia: intraperitoneal local anaesthetic in laparoscopic cholecystectomy: a randomized, double-blind, placebocontrolled study. Anesthesiology 1996;85(1):11-20.
15. Bamigboye AA, Justus HG. Ropivacaine abdominal wound infiltration and peritoneal spraying at cesarean delivery for preemptive analgesia. Int J Gynaecol Obstet 2008; 102(2):160-4.

16. Goldstein A, Grimault P, Henique A, et al. Preventing postoperative pain by local anesthetic instillation after laparoscopic gynecologic surgery: a placebo-controlled comparison of bupivacaine and ropivacaine. Anesth Analg 2000;91(2):403-7.

17. Vinson-Bonnet B, Coltat JC, Fingerhut A, et al. Local infiltration with Ropivacaine improves immediate postoperative pain control after haemorrhoidal surgery. Dis Colon Rectum 2002;45(1):104-8.

18. Callesen T, Hjort D, Mogensen T, et al. Combined field block and intra. Peritoneal instillation of ropivacaine for pain management after laparoscopic sterilization. British journal of anesthesia 1999;82(4):586-90.

19. Dreher JK, Nemeth D, Limb R. Pain relief following day case laparoscopic tubal ligation with intra-peritoneal ropivacaine: a randomized double blind control study. Australian and New Zealand Journal of Obstetrics and Gynaecology 2000;40(4):434-7.

20. Kim TH, Kang H, Park JS, et al. Intraperitoneal ropivacaine instillation for postoperative pain relief after laparoscopic cholecystectomy. J Korean Surg Soc 2010;79:130-6.

21. Malhotra N, Roy KK, Chanana C, et al. Post-operative pain relief after operative gynecological laparoscopic procedures with intraperitoneal bupivacaine. The internet journal of gynecology and obstetrics 2006;5(2).

22. Ducarme G, Sillou S, Wernet A, et al. Single-shot ropivacaine wound infiltration during cesarean section for postoperative pain relief. Gynecol Obstet Fertil 2012; 40(1):10-3. 